DOI: $10.36108 / \mathrm{ssan} / 1413002.9181 .0130$

\title{
Learned Academies and Social Responsibility ${ }^{1}$
}

\author{
Ayo Banjo
}

\section{Introduction}

At a time when the number of universities in the country seems to be increasing by leaps and bounds, we should recognize the special place of University of Lagos, which pioneered the offering of degree and postgraduate studies in the professions, at a time when the nation's premier university, the University of Ibadan, was still preoccupied with the traditional image of a university. The picture has changed somewhat since 1960, but the leadership of Lagos in professional studies has to be recognized; and I hasten to add that this has in no way jeopardised the University's excellence in all the other programmes that it offers.

The proliferation of universities in this country will inevitably lead us to the position in many other countries, where universities are categorized in terms of excellence. It is mere wishful thinking to expect that all the two hundred universities in the country will be of the same quality. When that categorization crystallizes, Lagos will surely be in the First Division, not because it is today described as a member of the so-called first generation of universities, but because, like a few other universities, it is the model to influence many of the universities at present being established, and those predictably to be established in the future. My hope is that, as in other countries, our First Division universities will receive a special attention both of the government and of the private sector.

I do congratulate this university on the fifty-second anniversary of its foundation, and on the steady stream of high-level manpower it has turned out to enrich the country culturally and professionally. Relevance has been the watchword for the university from its inception, and it is pleasant to notice how, over the years, the leaders of the university have positioned the institution to promote its relevance. To cite but one example, this university has a formidable Distance Learning Institute which has consistently striven to fulfil its mandate of providing, to quote its Prospectus, 'facilities for part-time studies in such fields as Business Studies, Accounting, Law and Education through correspondence and distance learning techniques.' If all universities in the country are

\section{Learned Academies}

It may at first sight seem superfluous to modify Academies as done in the title of this lecture; but there is, in fact, a good reason for doing so. The 'original' Academy, so to speak, was that established by Plato in the 4th century B.C. in a grove in Athens. According to Ajayi(2000):

'The Academy has been described as a school of political science. Its aim was to provide "an ethical and scientific training" on the Socratic principle that in the last analysis the student should be "more man than citizen." Using the 
tool of philosophy for analysis the Academy sought passionately "after the truth in all fields from mathematics to metaphysics."

Thus in Plato's Academy, all knowledge was pursued philosophically, and the tradition that the highest pursuit of knowledge is philosophical is shown even today in the fact that the highest degree awarded by a university in any discipline whatsoever is the Doctor of Philosophy (Ph.D.)

However, things have changed, as they must do in a dynamic world. The meaning of Academy as the embodiment of the acme of the pursuit of knowledge has today become more diffuse. Here in Nigeria, we have a secondary school for boys named Baptist Academy in Lagos, which is not the kind of Academy that Plato had in mind. I believe there are even primary schools in this country which go by the title of Academy. Such is the proclivity of Nigerians for big-sounding and imposing titles.

This trend would appear not to be confined to Nigeria, however. In recent years, the government of the United Kingdom has established a number of secondary schools which it calls Academies. This is presumably to signal the fact that the schools are designed to be better in quality than the normal run of secondary schools in the country. There is thus a certain prestige attaching to the title of Academy.

The title is even more widely used than this, in Nigeria as well as in other parts of the world. Thus we have Police and Military Academies, where it is most unlikely that knowledge is pursued in the Platonic sense. The reason is clear: PoliceAcademies aim at producing excellent policemen; Military Academies aim at producing excellent solders; but Academies after the tradition of Plato aim at producing intellectually excellent human beings, qua human beings. The reason for qualifying Academies in the title of this lecture should now be obvious: not all Academies are a collection of learned individuals concerned with the pursuit of knowledge at the very highest level.

\section{Learned Academies}

There is an obvious way in which modem Learned Academies differ from Plato's original. In the Socratic tradition, Plato's Academy was a teaching institution, where Plato sought to cultivate the minds of young Greeks in the manner earlier described. Modem Learned Academies, in contrast, tend to be a collection of individuals who are already eminent in their fields but who wish to give society the benefit of both individually and collectively. This is clear from the plethora of Academies which have sprung up all over the world.

\section{The French Academy}

The oldest, and certainly the best known, of the Learned Academies in Europe is the French Academy (Academic Francaise) established in 1635 by Richelieu. It consists of 40 members known as les immortales (the immortals), indicating the reverence in which both the Academy and its members are held. The motto of the Academy is 'To immortality.' 
The Academy was set up to keep the French language purified, which means, among other things, keeping borrowing from other languages minimal. There was a long argument, for example, before the word 'football' could be borrowed from English. The Academy's decisions on matters of French language usage are, however, advisory rather than legislative, but nevertheless very influential. The Academy publishes a dictionary as an obvious control mechanism.

As a result of the activities of the French Academy, it is common knowledge that the French language has been more strictly controlled than, say, the English language which, throughout its history, has borrowed voraciously from every language that it has come in contact with. While the French may be proud of the relative purity of their language, the English language has, in contrast, lent itself to domestication in different parts of the world - including Nigeria - where distinct local varieties of the language have emerged.

One can thus talk of Nigerian English in a way that one cannot speak of Senegalese French. The openness of the English to their language has helped to make the English language the most widely spoken language in the world, though the French language still retains something of its supremacy in the fields of diplomacy and cuisine.

However, the English language itself has not been entirely free of control. The control came through dictionary-making in the 18th century, as a result of the efforts of Samuel Johnson in England and Noah Webster in the United States of America. But the language has no body of immortals watching over the use of the language by mere mortals.

Other Academies followed in France in the trail of the French Academy, the preeminent Academy in the country. There are now, in total, five Academies. The Academy of Sciences was established in 1666, and the other three Academies are the Academy of Moral and Political Sciences, the Academy of Inscriptions and Belles Lettres, and the Academy of Fine Art.

With the Academy of Fine Art(s) we came to a slightly different form of an Academy, one which has gained popularity in many parts of the world. An Academy of Fine arts is devoted to performance at the highest level of the visual arts, the performing dramatic arts and music. The idea of an Academy as an institution dealing with the pursuit of ideas at the highest level has now been extended to include the pursuit of performance of the arts at the very highest level. There are Academies of Fine Arts all over Europe, just as there are Academies of Music - for example, the Academy of St. Martins in the Fields in London, whose founder and conductor, Sir Neville Mariner, has, incidentally, just turned 90 and is still conducting!

Even better known are Academies of Dramatic Arts, made famous by the activities and celebrations of Hollywood. What these other Academies have in common with the Learned Academies is the pursuit and recognition of perfection. Besides, performances in the Fine Arts can generate esoteric discussions, which bring them close to the preoccupations of the Learned Academies. 


\section{The British Academy}

The British Academy, founded in 1902 by Royal Charter, was set up 'to inspire, recognize and support excellence in the Humanities and the Social Sciences throughout U.K. and internationally.' (Wikipedia). Unlike the restricted membership of the French Academy, the British Academy has hundreds, or perhaps thousands, of members. It is the ambition of every outstanding scholar in the Arts and the Social Sciences in Britain to have the letters FB A (Fellow of the British Academy) after his or her name, just as it is the ambition of the most distinguished scientists in the country to have the letters FRS (Fellow of the Royal Society) after their names.

The Academy receives the support of the British government, which obviously recognizes the important role that the Academy can play in national development. An annual grant of about thirty million pounds is made to the Academy through the Department of business, innovation and skills to emphasize this role.

Britain does not have an Academy of Science, but rather the Royal Society, which is in every way as prestigious as the British Academy. Indeed, the Society receives greater funding from the British government in recognition of the increasing role that science plays in the development of the country. The country also has a number of other Academies which cannot be strictly categorized as being learned. There are, for example, the British Academy of Management, and the British Academy of Interior Design.

With the latter, we see the way that, as in France, Britain also has Academies in the Fine Arts to encourage the highest degree of creativity. Reference has already been made to the Academy of Music, but we also have the famous British Academy Film Awards in the field of Drama.The international dimension of Academies in Britain is illustrated by the British American Academy, but the British Nigerian Academy appears to be an extension of the application of the title of Academy to secondary schools. The British Nigerian Academy is in fact a boarding school in Abuja.

\section{American Academy of Arts and Science}

The American Academy of Arts and Sciences, frequently referred to simply as The American Academy, is the United States' premier Academy. It was founded in 1780. It is the country's 'oldest and most prestigious honorary society and leading centre for independent research in the US'(Wikipedia). The Academy's motto is highly instructive:

To cultivate every art and science which may tend to advance the interest, honour, dignity and happiness of a free, independent, and virtuous people.'(Wikipedia).

The Academy's quarterly Journal, Daedalus is reported to be widely regarded as one of the world's leading intellectual Journals.

The United States also has a fairly large number of other Academies, illustrating the way in which, as remarked earlier, the term has acquired an increasingly diffuse connotation in 
recent times. With the break-down of disciplines in an era of increasing specialization in the last three centuries, it is now a far cry from Plato's Academy which pursued all knowledge in one single Academy employing philosophy as the all-encompassing methodology. Thus there are the American Academies of Arts and Letters, as well as the Academy of Arts, dealing with creative arts.

There is also, in particular, the American Academy of Dramatic Arts, founded in 1884. It would appear that there is an overlap of concerns among these Academies, To further complicate the picture, there are American Academies of Neurology, Ophthalmology, Financial Management, etc. It is clear from this that the United States seeks perfection in every area of activity and has bodies established to aid the pursuit of excellence.

\section{The Russian Academy of Sciences}

The Russian Academy of Sciences, Russia's premier Academy, was established in 1724 as a 'civil, self-governed, non-commercial organization chartered by the government of Russia.' The Academy has branches all over the country, which indicates the premium that Russia placed on science in the early eighteen century, at the beginning of the Enlightenment in Europe.

Much later, however, in 1783, the Russian Academy was established by Catherine II of Russia. This new Academy was devoted to Language and Literature, and produced the Academic Dictionary of Russian. It was, however, merged with the Academy of Sciences in 1841.

The other important Academy, the Academy of Arts, established in 1757, is concerned with Fine Arts only, following the pattern which we have noticed in France, Britain and Russia, where some Academies are concerned exclusively with creative and performing Arts. Learned Academies and other varieties of Academies are, however, not the exclusive preserve of Europe and America but are recognized as a veritable tool for development universally.

\section{Japanese Academy of Sciences}

The Japanese Academy of Sciences was founded in 1879 'to bring together leading Japanese scholars with distinguished records of scientific achievements. Election to the Academy is considered the highest distinction a scholar can achieve' (Wikipedia). Unlike in other countries, however, and perhaps not surprisingly, the Academy is attached to the country's Ministry of Education. Membership is for life and, in contrast to the membership of Academies of other countries, attracts monetary stipend.

Outside of the sciences, there is a Japanese Academy in the area of Cinema. This Academy makes annual awards to those who have excelled in various aspects of film-making. The other Academy is the Academy of Martial Arts. Japan is famous for its martial arts, and it is therefore hardly surprising that an Academy should devote itself to excellence in this area. 


\section{Chinese Academy of Sciences}

There are four well-established Academies in China, the most prominent of which is the Academy of Sciences, established in 1949. Its remit is very much the same as in the Academies of Sciences that we have previously considered.

The Chinese Academy of the Social Sciences, established in 1977, has very wide concerns which include Philosophy, Literature, History, Economics, Law and Political Science. This shows the different ways in which different countries may group academic disciplines together under the same Academy. As we have seen, even Science and Arts (or Humanities) may sometimes be grouped together under the same Academy.

There is also a Chinese Academy of Agricultural Sciences, founded in 195 7, which undertakes agricultural research and development. It plays an important role in' solving the fundamental and strategic technological issues in Agriculture and rural economic development...integrating agriculture with science and technology' (Wikipedia). Thus we find that this is really a hands-on Academy, which is hardly surprising in view of China's large population and the consequent food requirements. The same demographic challenges would explain also the existence of a Chinese Academy of Medical Sciences.

\section{Indian Academy of Sciences}

The Indian Academy of Sciences was established in 1934. This was thirteen whole years before India became independent, and it explains why, in spite of the large population of India, its scientific progress has been impressive, culminating recently in the country's entry into space exploration. The Academy's objectives are similar to those of other Academies of Sciences elsewhere, and include advising the government and other bodies on scientific and other matters referred to the Academy. In addition, India has a number of other subject-specific Academies such as the Academy of Paediatrics and the Academy of Neurology.

The Academy of Paediatrics, established in 1962, has the main function of organizing continuing medical education, obviously to cope with problems arising from the country's teeming population.

In summary, Learned Academies would appear to be indispensable catalysts for development in developed and seriously developing countries of the world, as our brief survey has shown. From Plato's Academy's dispassionate search for knowledge for the development of the individual, modem Learned Academies have been modified down the centuries to combine also national development in their remit.

That Academies are associated with the search for perfection is reflected in the use of the label by other bodies seeking perfection in their various areas of activity which cannot be construed as being learned.

We may consider four ways in which modern Learned Academies unobtrusively play their role. Given the increasing importance of science and technology to knowledge production 
generally as well as to national development from the eighteenth century onwards in Europe, it is hardly surprising that every country places a high premium on its Academy of Sciences. Indeed, someAcademies of Sciences also encompass disciplines which are not usually classified as belonging to physical science in the strict sense.

The inclusion, in some cases, of the social sciences in such Academies is perhaps not surprising, though there is a world of difference between sociology and physics. An Academy of Sciences thus provides an overarching umbrella under which the scientific development, and consequently national development, of a country can be pursued at the very highest level, for this reason, Academies of Sciences usually enjoy generous funding from their governments, to enable them to stimulate research in various fields.

At the same time, it can be claimed that it is the Academies of Arts or Letters that are the more direct successors to Plato' academy. Such Academies emphasize that development is, in the first place, about people. To emphasize manpower development at the expense of human development may lead to seemingly intractable problems, such as pervasive corruption.

In the second place, Members (or Fellows) of Academies are important role models in society, and may serve as mentors to the younger generation of scholars. Learned Academies are highly prestigious institutions, and the Fellows are held in reverence by other scholars, who aspire to join their ranks. As we have seen, the members (equivalent of Fellows) of the French Academy are referred to as 'The Immortals.' Learned Academies therefore cannot but serve as a strong encouragement to universities and research centres to aim at perfection; and very high standards in the universities and research centres will translate into the training of high calibre manpower at the service of the entire nation.

Thirdly, Learned Academies are usually engaged in publications of the highest quality, and in the organization of lectures, to advance knowledge. In some cases, as in the French and Russian Academies, they also engage in the publication of authoritative dictionaries which benefit the entire country in each case. To be able to perform this role creditably, the Academies would, of course, expect financial support from their governments.

Finally, some Learned Academies, such as the Chinese Academy, are engaged in hands-on engagement in specific projects to boost national development. This they do by working closely with the relevant Ministries, particularly the Ministry of Education. By bringing their expertise to bear on such projects, they help to ensure that the best possible results are achieved, while other scholars are given the opportunity of working side by side with people regarded as legends in their fields.

\section{Nigeria's Learned Academies}

It was to be expected that Learned Academies would spring up in Nigeria, at least in the wake of the country's independence. The surprise is that it took so long for this development to take place. The Indian Academy, as we have noted, was established even while that country was still a British colony, and thirteen years before the country became independent. 
One of the landmark recommendations in the famous Udoji Report, released in 1974, was that a National Academy of Arts and Sciences should be established in the country. Obviously, the members of the Udoji Commission had observed the very useful role that Learned Societies were playing in other countries, and were anxious that Nigeria should avail itself of similar benefits from its most gifted scholars. The government accepted this recommendation but decided to split the Academies into the Science, Humanities, Education and Social Sciences Academies, to which Engineering was later added.

\section{The Nigerian Academy of Science}

The Nigerian Academy of Science (Sometimes referred to as the Nigerian Academy of Sciences) was established in 1977, three years after the publication of the Udoji Report. It is thus the oldest of the Nigerian Academies and has, particularly in the past ten years or so, engaged in vigorous advocacy for the application of science to the solution of the country's problems, and for the creation of a scientifically enlightened citizenry. It has argued its case right up to the National Assembly and in fact receives an' annual subvention from the government - the only Nigerian Learned Academy to receive this kind of support.

The existence of the Academy was brought more firmly into public consciousness ten years ago when the Nigerian Liquefied Natural Gas Company (NLNG) invited the Academy to partner with it in the organization of an annual Nigeria Prize for Science, which at the moment is going for the princely sum of $\$ 100,000$. There is no doubt that the Academy has its work cut out for it in trying to bring Nigeria up to the scientific and technological modern era.

The Nigerian Academy of Education was the second Academy to come on stream. It was inaugurated by the incumbent Head of State, no less, and given a generous subvention as seed money. It is not clear whether further subventions have been made to the Academy since then. Like the Academy of Science, this Academy also attempts to influence government policy through the regular annual lectures at its conventions, and at other fora. Nigerian education at present is in need of some bold and original thinking in its form and content, and there is a lot that the Academy of Education can do in this direction.

The Nigerian Academy of Letters was established in 1990 through the initiative of some very senior professors based at the Faculty of Arts of the University of Ibadan. Unlike the earlier Academies, it has received neither seed money nor any regular subvention from the government, but only recently has been able to tap into the resources of the Education Tax Fund (ETF).

The Academy makes its presence felt nationally through its annual Convocation, at which a lecture on a topic related to the prevailing national condition is given by a noted scholar, and new Fellows are admitted to the Academy. It also, like the other Academies, engages in publications.

The importance of this Academy and its potential to transform the country cannot be over-emphasized, for the Academy emphasizes man-centred development, without which, ultimately, all other forms of development would be both laborious and transient. 
It would be true to say that the above are the three main Academies in Nigeria. However, it is necessary to add that there is an Academy of Social Sciences, which has its origins in the Social Science Council of Nigeria. This Council was not conceived as a Learned Academy at inception as can be seen from the expansive membership, which is open to scholars and non-scholars alike. It would perhaps be fair to say that the process of transforming this Council into a Learned Academy is still ongoing and that, when completed, the result should add value to the intellectual climate of the country and stimulate its social and economic development.

The Academy of Engineering is the latest addition to the number of Academies in the country, having evolved from the Academy of Science. Indeed, some scholars hold dual Fellowship of the two Academies.

That the five Academies have, at least, been noticed by the federal government, if not formally recognized, is shown in the fact that provisions were made for all of them to be represented on the 2014 National Conference.

The term 'social responsibility' is often used in the context of corporate social responsibility, where it connotes the awareness on the part of commercial firms of the virtue of voluntarily giving something back to society over and above the taxes that they mandatorily pay. We may say that the social responsibility of LearnedAcademies refers to the service that their Members and Fellows voluntarily undertake to render corporately to the country over and above what may be their paid occupations. In Nigeria, as in Britain, some Fellows are serving professors in the universities while others are retired professors. In either case, they receive no remunerations for being Fellows but nevertheless act as important catalysts to the growth of knowledge and its application to the process of national development.

None of Nigeria's Learned Academies is fully developed yet, but as we have observed in our survey of Learned Academies in other countries, while Members and Fellows of Academies give of their time freely to promote knowledge in various disciplines, it behoves the government of a country, in appreciation of the Academies' efforts, and in clear understanding and appreciation of the developmental potentials of these efforts, to support them financially and, even more importantly, to under write searches and other projects brought up by them. It has to be said that the government of this country is yet to show clear appreciation of the potentials of the five Learned Academies in existence. None of them, with the possible exception of the Academy of Science, enjoys regular financial support from the government. In terms of recognition, attempts are just being made to give legal recognition to the Academies.

A Bill sponsored by the Academy of Science is already before the National Assembly; but fresh thinking on the matter has brought up the desirability of having one omnibus law forall the Academies, with a section devoted to each one of them. Discussions are ongoing among the Academies which may result in such an omnibus law. The alternative would be for each Academy to seek for its own law, which would, among other things, be administratively less tidy. 
Indeed, the possibility of all the Nigerian Learned Academies having a forum for cooperation has been considered in the past. An umbrella organization for the Academies, to be known as the Association of Nigerian Academies, was proposed. Unfortunately, the idea did not materialise at the first attempt, but it has not been completely given up yet.

The proposition to have all the Academies in continual communication with one another cannot be a bad one. It would make it possible for issues to be discussed even at inter-Academic levels, facilitating inter-disciplinary collaboration across the whole spectrum of the Nigerian intellectual universe. We would do well to remember that there was only one Academy in Plato's time, and that it was able to engage in all that was known of knowledge at the time. In spite of the fine specializations that have come about since then, it would be salutary, surely, to be reminded of the ultimate interrelatedness of all disciplines.

Academies of Science and Arts (or Letters, or Humanities) seem to be the minimum in all the countries that we have examined. This is in keeping with the traditional division of all knowledge. Where we have Academies of Sciences, they tend to include physical as well as social sciences; but in other countries, such as Britain, the social sciences are included in the arts. This reflects the Janus posture of the discipline.

It is left to each country to decide not only the number of Learned Academies to have, but also the internal composition of each Academy, and these are usually decisions to be freely taken by the intellectual leaders of the country.

Since in Nigeria, as elsewhere, such leaders take the decision in the light of what they regard as the areas vital for national development, it may be useful to examine how relevant the existing five Academies are.

It is generally recognised that Nigeria faces gargantuan problems in the area of education, on which genuine national development ultimately depends. The Academy of Education thus has its work cut out for it. The entire education system needs to be subjected, as already suggested, to a bold and original thinking, paying greater attention to Nigeria's unique problems than to the facile borrowing of practices from abroad. Primary and secondary levels of education need to be entirely reconstructed to provide, on the one hand, suitable inputs into the tertiary level, and on the other hand, to produce truly civilized, morally upright and refined Nigerians. The transition from the secondary to the tertiary levels also requires careful thinking. It is difficult, for example, to see the justification for abolishing the Sixth Form, which worked reasonably well, and substituting instead a system which from the beginning has been problematic. The Academy also needs to speak up on the thorny subjects of the funding of the universities, and on university autonomy. Unfortunately, there is a feeling in some quarters that, given the involvement of the Federal Ministry of Education in the affairs of this Academy, the tendency for it may be to be inclined to toe the official line of the establishment. This, if it proves to be true, would be a tragedy.

We live in a scientific and technological age, and this must be reflected in the country's education system. This shows the way in which the Academies of Education and of Science have to work together towards a common end. The Academy of Science must give guidance 
on the science content of Nigerian education, particularly at the primary and secondary levels. But outside the formal education system, the country also looks up to the Academy of Science for guidance and leadership, and its role here is in two important dimensions.

In the first place, it has to help in unearthing whatever science content there was and still is in the indigenous cultures of Nigeria, since it is inconceivable for a race of human beings to survive for thousands of years without even the most elementary scientific activity. It is perhaps a question of definition. It is well known that the indigenous cultures of Nigeria were seriously disrupted in the nineteenth century, and that since then, science has been considered as the exclusive preserve of Europe and America. By discovering the way in which science was practiced in the ancient cultures of Nigeria, a way may be discovered of providing linkages between this and modern science.

This, however, is not to deny that modern science looks alien to the ordinary Nigerian, particularly in the rural areas; and an important part of this has to do, surely, with the use of language. Modem science in Nigeria is practiced in the English language, which immediately shuts out the overwhelming majority of Nigerians: The efforts of linguists may yet provide a method of making modern science yield its secrets even to monolingual Nigerians by establishing a meta-language which provides equivalents between the ancient Nigerian apprehension and analysis of natural phenomena and the modem, Europeanised mode.

The other dimension in which the leadership of the Academy of Science is vital is in helping to infuse the scientific attitude and method into the indigenous cultures of Nigeria, so that modern science becomes fully domesticated in the cultures. One simple way of doing this is by giving enough prominence to scientists in the public life of the country as is the case in developed countries.

The public needs to be exposed constantly to rational explanations of phenomena instead of having the mysteries of the unknown reinforced. Scientists need to be more in evidence in the media, helping the public to acquire the scientific attitude. A comparison, for example, of science-based programmes on television broadcast in Britain and in Nigeria shows a preponderance of such programmes on British television and hardly anything at all on Nigerian television. The result is that the viewer in Britain is helped to understand, and be at home in, the world he lives in, whereas his Nigerian counterpart continues to live in a world which is largely mysterious.

Mention has been made of the language factor in the acquisition of the scientific attitude, and we may dwell on this a little further. But first, let us observe the fact, already alluded to, that Academies are dependent on one another. Amodem education system seriously deficient in science cannot be satisfactory; but then, as already observed, language plays a major role in the design of a science curriculum in a country like Nigeria. The language factor looms as large in the Nigerian education system as the science factor. In this way, the interdependence of the three Academies can be demonstrated.

The Academy of Letters is the one Academy that we can look up to for guidance in the almost intractable language question in Nigeria, in and out of the education system. Within the education system, there is research evidence from the University; of Ife to show that 
teaching in the mother tongue in the early years of schooling is far more productive than going' straight for English'. This is recognized even by the current national policy on language in education, which has been severely ignored. As a result, hardly any effort has been made to take advantage of these research findings by incorporating in schools the method which has been proven to be superior. It should, in addition, be recognized that the current unsatisfactory level of proficiency in English among secondary school leavers is a direct reflection of the current inefficient practice in schools. Even proficiency in all the other subjects on the curriculum also stands to benefit from the adoption of the findings of the Ife project.

The Academy of Letters would be making a very significant contribution to national development if it can influence the adoption of the superior choice of languages of instruction in schools. This would imply, among other things, a concerted effort to develop the country's indigenous languages. A beginning in this direction was made a few years ago but not enough progress has been registered.

Outside the education system, there are even more important roles for the Academy to play. The number of languages spoken in the country tends to be given in broad approximations. The Academy can galvanize a country-wide research which will improve our knowledge in this area. A reliable linguistic atlas of the country can thus be produced to improve Nigerians' knowledge of their own country.

The position of the English language in the country has naturally attracted a great deal of attention among Nigerian linguists. The description of an end on normative standard of English is a possible outcome of this attention. The Academy can bring its influence to bear on these efforts. While we would not recommend that the Academy should follow the footsteps of the French Academy in prescribing correct usage, it should be possible for it eventually to coordinate efforts to produce a Nigerian dictionary of English which would provide guidance in and out of the school system.

On the question of a national language for the country, a lot of work has already been done in this area by Nigerian linguists, led by Ayo Bamgbose. No national policy has emerged, for reasons which are not difficult to surmise, but the Academy will, hopefully, continue to nudge the policy makers in the right direction.

There are other equally pressing matters demanding the leadership of the Academy. Humanistic studies are uniquely preoccupied with total human development, as distinct from manpower development. They are profoundly interested in human values, including morality and aesthetics. And they are interested in the kind of self-awareness which traces the conditions of human groups from as near the origins as possible, so that the groups can position themselves realistically for future development. For such an exercise, the study of history is vital, and it is nothing short of embarrassing that the study of History has been removed from the curriculum in Nigerian schools. The Academy of Letters is making its views clearly heard on this subject, and it is expected that it will not rest until the study of History is restored in schools.

Every modern country is passionately concerned with economic well-being and development; and Nigeria is no exception. With the emergence of the world into a so-called global village, 
the Academy of Social Sciences has the sacred duty of protecting Nigeria's corner, to prevent exploitation by more advanced economies and to ensure the optimal utilization of the country's human and material resources. This is particularly important as the economies of all the countries in the world become more intricately intertwined and self-interest is the mantra of every country.

In view of the fact that the resources of the country lie largely undeveloped, the Social Science Academy of Nigeria is expected to give guidance on the best course of rapid development.

Science and technology tend to be taken together for obvious reasons, but in a developing country like Nigeria in a hurry to establish adequate infrastructure, the need for a separate Academy of Engineering becomes obvious. Perhaps the most urgent task before this Academy is to bring about the development of technical education in the country. The trend today is for all products of secondary schools to try to enter the university. So desperate are many of them that fraud and cheating have crept into the examination processes at the school certificate and JAMB levels. The reason for this undesirable development is that pupils and their parents believe that the university alone leads to success in life.

Technical education is in urgent need of development in the country so that the problems of an adequate infrastructure can be squarely met. Part of the reform necessary is a revision of career prospects for the products of technical education. At the moment, even Colleges of Education and Polytechnics are all too often viewed as conduit pipes into the universities. There is need for the Academy of Engineering to fight for better prospects for the products of these colleges. That way, the polytechnics will attract students who are as academically sound as those entering the universities, and the result will be obvious in the quality of our environment.

The Academy also needs to be concerned about the quality of engineering graduates from our universities. There are sometimes complaints about their training being more theoretical than practical. All in all, we are still waiting for engineering feats to be performed by Nigerian engineers. Together with the academy of Science, the Academy of Engineering can do a lot to improve the quality of life of Nigerians.

There is a lot that Nigerian Learned Academies, acting individually or jointly, can do to improve the quality of life by influencing the production of the highest quality manpower by the Academies of Science, Social Sciences and Engineering. But even more important is the production of fully developed human beings by the Academies of Letters and of Education. Together, all the Academies have an important role to play in hastening the entry of Nigeria into the twenty-first century, even at this late stage, and ushering in an era of fulfilled and happy citizens.

It bears repeating that the Academies do not get paid for what they do, but are engaged in freely giving back to society the benefits of their learning. However, everywhere, a government realizes the importance of the contributions of the Academies and funds them for their internal administration and for various projects they may decide to embark on. It is therefore 
hoped that the Act in the offing to grant recognition to the Academies will be promulgated as early as possible and that funds for running their internal administration will be provided on an annual basis.

Meanwhile, Nigerian Academies are indebted to a number of stakeholders who give financial support, particularly to their projects. The NLNG is such a stakeholder, but particularly worthy of mention in this connection are two of our leading universities. The University of Lagos led the way by providing permanent accommodation on its campus for the Academies of Science and Letters, in a building which it has appropriately named 'Academy House.' This is an invaluable contribution to the functioning of the two Academies. Later, the University of Ibadan followed suit by donating a building on campus to the Academy of Letters. It is encouraging, though not surprising, that recognition for the work of the Academies should come so conspicuously from the universities, and it is altogether appropriate that this discussion of the Learned Academies should take place at the University of Lagos.

\section{References}

Ajayi, J.F. Ade (2000) Development Is About People. In Banjo, A(ed) Humanity in Context. Ibadan: Nigerian Academy of Letters. Wikipedia

\section{Footnotes}

${ }^{1} 2014$ Convocation Address at the University of Lagos, Akoka, Yaba 